\title{
RECEPTORES GPS DE TRÊS PRECISÕES E ESTAÇÃO TOTAL NA CARACTERIZAÇÃO DE COTAS BÁSICAS PARA PROJETOS RURAIS
}

\author{
VILMAR A. RODRIGUES ${ }^{1}$, LINCOLN G. CARDOSO ${ }^{2}$, LUCIANO N. GOMES ${ }^{3}$, \\ ZACARIAS X. DE BARROS ${ }^{2}$, SÉRGIO CAMPOS ${ }^{4}$
}

\begin{abstract}
RESUMO: O objetivo deste estudo foi comparar cotas de vértices de uma poligonal, considerando dados coletados por três diferentes receptores GPS, usando como testemunha uma estação total. Os dados foram obtidos em uma poligonal fechada, sendo posteriormente tratados pelo software Topograph. As cotas obtidas pelos três receptores foram confrontadas com aquelas calculadas a partir do levantamento com a estação total, mediante a aplicação do teste "t", constatando-se que as mesmas foram satisfatórias para o equipamento GPS Trimble ${ }^{\circledR} 4600$ LS. Para o equipamento GPS Trimble ${ }^{\circledR}$ modelo PRO XR, as cotas não foram totalmente satisfatórias, mas possíveis de serem consideradas em anteprojetos. Para o equipamento GPS Garmin $^{\circledR}$ de navegação 12 XS, as cotas mostraram-se inaceitáveis para a finalidade estudada.
\end{abstract}

PALAVRAS-CHAVE: cotas, estação total, GPS.

\section{RECEIVING GPS OF THREE PRECISION AND TOTAL STATION IN THE CHARACTERIZATION OF BASIC COTA FOR RURAL PROJECTS}

\begin{abstract}
The objective of this work was to compare cotas of polygonal vertices, through three different receiving GPS, using as reference a total station. The data were obtained in a closed polygonal, being treated later by the software Topograph. The cotas obtained by the three receivers were confronted with those calculated by means of the application of the test, being verified that the cotas were satisfactory for the equipment GPS Geodesic Trimble ${ }^{\circledR} 4600$ LS. For the equipment GPS Trimble ${ }^{\circledR}$ topographical model PRO XR, the cotas weren't totally satisfactory, but possible of being considered in preliminary projects. For the navigation equipment GPS Garmin ${ }^{\circledR} 12 \mathrm{XS}$ the cotas were shown unacceptable for the studied purpose.
\end{abstract}

KEYWORDS: cotas, total station, GPS.

\section{INTRODUÇÃO}

Levantamentos planialtimétricos topográficos ou geodésicos - quer seja nas áreas de irrigação e drenagem, execução de barragens, sistemas de abastecimento de água e esgoto sanitário ou área civil são fundamentais, tendo em vista que todo o projeto necessita de planta topográfica (SILVEIRA, 2000).

Nas últimas décadas, a área da mensuração (topografia, geodésia, etc.) sofreu modificações importantes. Na topografia, os teodolitos mecânicos foram substituídos pelos teodolitos eletrônicos, surgiram os medidores eletrônicos de distância (distanciômetros), os quais, recentemente, foram incorporados aos teodolitos eletrônicos formando as Estações Totais (Total Station); os níveis mecânicos estão sendo substituídos pelos níveis digitais e níveis a laser. O avanço mais importante, entretanto, ocorreu com o aparecimento do sistema de medições por satélites - GPS, que vem revolucionando a área de levantamentos, embora outros sistemas, como o GLONASS e o GALILEO

\footnotetext{
${ }^{1}$ Engo ${ }^{\mathrm{o}}$ Agrimensor, Aluno de Doutorado em Irrigação e Drenagem, FCA/UNESP, Botucatu - SP, vilmar@ goeproj.unesp.br

${ }^{2}$ Eng ${ }^{\mathrm{O}}$ Agrônomo, Prof. Titular, Departamento de Engenharia Rural, FCA/UNESP, Botucatu - SP, cardosolg@ fca.unesp.br

${ }^{3}$ Eng o Agrônomo, Aluno de Mestrado em Irrigação e Drenagem, FCA/UNESP, Botucatu - SP, lunago@ @ca.unesp.br

${ }^{4}$ Eng ${ }^{\mathrm{O}}$ Agrônomo, Prof. Adjunto, Departamento de Engenharia Rural, FCA/UNESP, Botucatu, seca@ @ fca.unesp.br

Recebido pelo Conselho Editorial em: 29-6-2004

Aprovado pelo Conselho Editorial em: 17-3-2006
} 
também fazem parte dos avanços na área. Paralelamente ao desenvolvimento de novos instrumentos, o aparecimento de programas aplicativos de topografia e geodésia, do Sistema de Informação Geográfica (SIG) e da Modelagem Digital de Terreno, vêm estabelecendo nova conduta na coleta, no tratamento dos dados e na apresentação dos resultados (SILVA \& ERWES, 1996).

O rápido avanço da tecnologia na área de mensuração topográfica e representação de áreas trouxe a necessidade de estudos visando a balizar a aplicação prática com segurança, de tal maneira a se evitar usos indevidos de equipamentos e procedimentos. Dentro dessa linha de raciocínio, o presente trabalho procura oferecer sua contribuição, notadamente no que tange à possibilidade do uso de receptores GPS de diferentes precisões na caracterização da altimetria de áreas.

\section{MATERIAL E MÉTODOS}

Para a realização deste trabalho, foram utilizados os equipamentos: Estação Total Nikon ${ }^{\circledR}$ modelo DTM 300, com precisão de $\pm\left(5+3\right.$ ppm x D) mm; GPS Geodésico Trimble, ${ }^{\circledR}$ modelo $4600 \mathrm{LS}$, 8 canais, portadora L1, código C/A e software Survey, versão 2.30; coletor Trimble ${ }^{\circledR}$ System Controller (TSC1), com firmware Survey Controller, versão 6.5; GPS Pathfinder Trimble, ${ }^{\circledR}$ modelo PRO XR, portadora L1 e código C/A e software TRS, arquivos em formato SSF; coletor Trimble Datalogger Controller (TDC1), com firmware Survey Controller, versão 2.7; GPS de navegação Garmin, ${ }^{\circledR}$ modelo 12 XL, com 12 canais, marcos de concreto em formato circular com $30 \mathrm{~cm}$ de altura e 10,16 cm de diâmetro, contendo barra de ferro central de $10 \mathrm{~cm}$ de altura. As coordenadas foram atribuídas aos marcos da poligonal, sendo utilizado o software Topograph, versão 3.1., no tratamento dos dados obtidos pela Estação Total.

A poligonal foi materializada instalando-se marcos de concreto, de forma aleatória, formando um polígono irregular com 19 vértices, protegidos por calçada de raio de $0,25 \mathrm{~cm}$, sendo utilizados quatro equipamentos na coleta de dados.

No levantamento realizado com a Estação Total Nikon ${ }^{\circledR}$ DTM 300, foi utilizado o método de ré e vante, compensando o erro obtido. Com o receptor GPS Geodésico Trimble, ${ }^{\circledR}$ modelo 4600 LS, na coleta de dados, o rastreio foi executado com o método estático relativo, utilizando a portadora L1 de 12 épocas. Uma das antenas (base) ocupou um marco de coordenada conhecida, vértice homologado pelo IBGE sob $n^{\circ}$ 91613, rede GPS USP, localizada em Jaboticabal - SP, e a outra antena (móvel) percorreu a poligonal já materializada, fazendo a inicialização por 20 minutos para resolução da ambigüidade, dando continuidade ao levantamento dos demais vértices.

Para o receptor GPS Pathfinder Trimble ${ }^{\circledR}$, modelo PRO XR, a antena fixa (base) fica capturando dados em um marco de coordenadas conhecidas, vértice homologado pelo IBGE sob $\mathrm{n}^{\circ}$ 93623, rede GPS da Santiago e Cintra, localizado em Quatá, utilizando o código C/A, sendo a captura dos dados dessa antena realizada via Internet, em bloco, a cada 1 hora. A antena móvel percorre a poligonal já materializada, coletando dados na taxa de 5 em 5 segundos.

Para o receptor de navegação Garmin ${ }^{\circledR}$, GPS 12 XL, o processamento dos dados levantados foi executado em tempo real, sendo os resultados (latitude e longitude) anotados em caderneta de campo. Os resultados obtidos com os três receptores GPS, no plano de referência Geodésicas Datum WGS-84, foram processados e transformados para o sistema de coordenadas UTM, no Datum SAD69.

Os dados coletados pela Estação Total foram calculados utilizando o software Topograph, versão 3.1, obtendo-se o perímetro da área, bem como os valores de cotas dos pontos representativos de seus vértices. Com a cota de referência em UTM, foi considerado o valor lido pelo receptor geodésico no marco 1. 
Os valores de cotas obtidos pelos três receptores foram comparados com os valores de cotas calculadas com base nos dados provenientes dos levantamentos com a estação total, utilizando-se dos testes de hipóteses e teste "t" de duas variáveis (nível de significância de 5\%).

\section{RESULTADOS E DISCUSSÃO}

Na Tabela 1, são mostrados os erros de fechamento da poligonal realizado com a Estação Total Nikon, ${ }^{\circledR}$ modelo DTM 300. Os erros obtidos estão em conformidade com os limites de tolerância recomendados pela NBR 13.133 da ABNT (ASSOCIAÇÃO BRASILEIRA DE NORMAS TÉCNICAS, 1994). Segundo essas normas, o erro máximo admitido nessa poligonal de fechamento angular é de $0^{\circ} 01^{\prime} 29$ " e o erro relativo é de 1:2000 a 1:5000. Constata-se, pelos valores apresentados, que a estação total se constituiu em segura testemunha, concordando com BERALDO \& SOARES (1995). Na Figura 1, é apresentada a poligonal estudada.

TABELA 1. Erros de fechamento da poligonal levantada com a Estação Total Nikon ${ }^{\circledR}$ DTM 300.

\begin{tabular}{lc}
\hline Erro Angular & $0^{\circ} 00^{\prime} 25^{\prime \prime}$ \\
Erro Linear & $0,1451 \mathrm{~m}$ \\
Este ( X ) & $-0,0170 \mathrm{~m}$ \\
Norte ( Y ) & $0,1441 \mathrm{~m}$ \\
Erro Relativo & $1: 59.305$ \\
Erro Altimétrico & $0,008 \mathrm{~m}$ \\
\hline
\end{tabular}

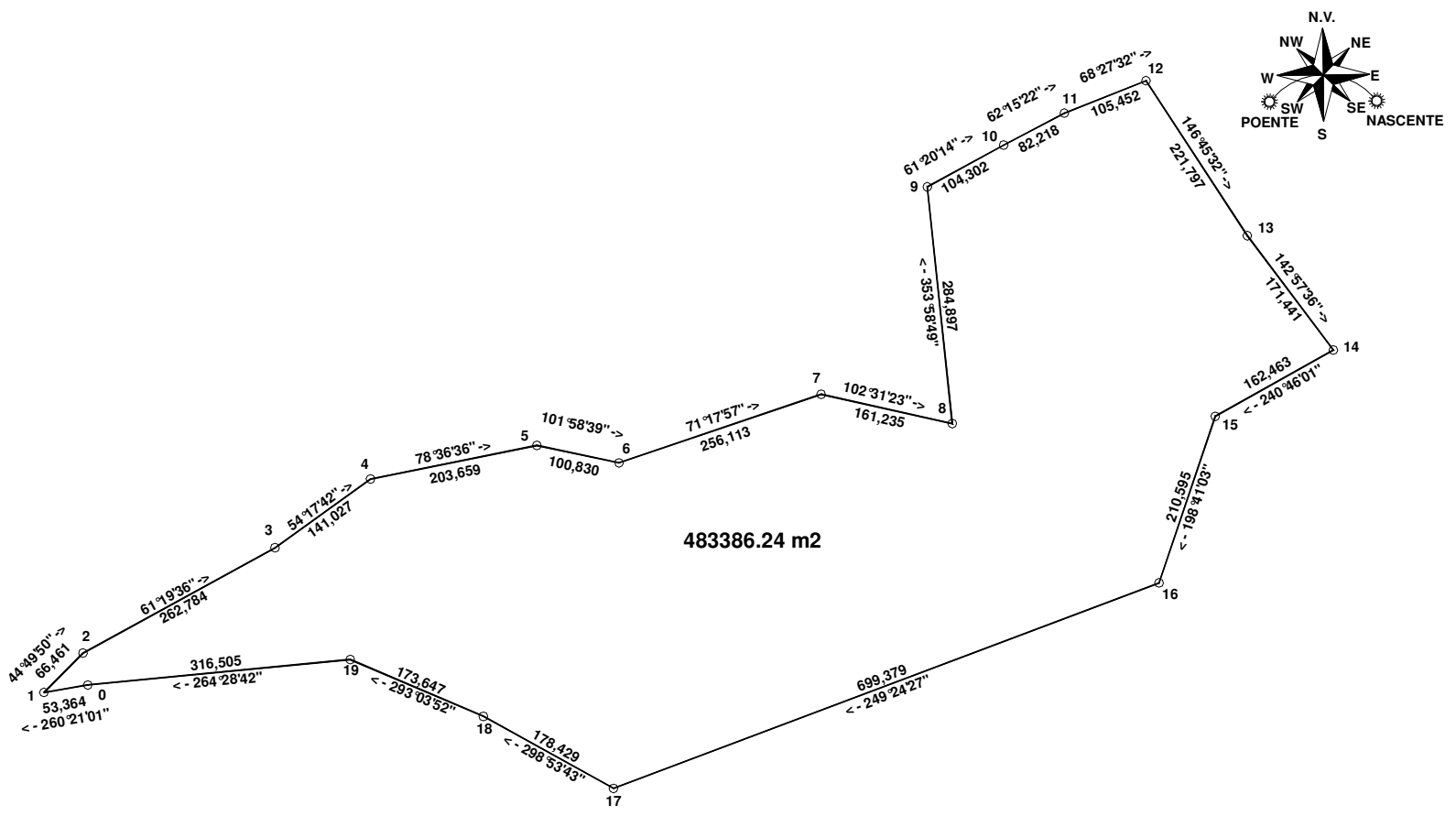

FIGURA 1. Poligonal obtida com o equipamento Estação Total Nikon ${ }^{\circledR}$ DTM 300.

Na Tabela 2, são apresentados os valores comparativos das cotas obtidas com os equipamentos de medição GPS Trimble ${ }^{\circledR}$ geodésico, 4600 LS, GPS Trimble ${ }^{\circledR}$ topográfico, modelo PRO XR e GPS Garmin $^{\circledR}$ de navegação 12 XL em comparação com a Estação Total Nikon ${ }^{\circledR}$ modelo DTM 300. 
Embora os valores obtidos pelos receptores sejam em altitude, optou-se por utilizar o termo cota, pela sua maior abrangência em atividades rurais.

TABELA 2. Cotas dos receptores GPS e Estação Total.

\begin{tabular}{ccccc}
\hline Ponto & $\begin{array}{c}\text { Estação Total Nikon }^{\circledR} \\
\text { DTM 300 }(\mathrm{m})\end{array}$ & $\begin{array}{c}\text { GPS Trimble }^{\circledR} \\
4600 \text { LS }(\mathrm{m})\end{array}$ & $\begin{array}{c}\text { GPS Trimble } \\
\text { PRO XR }(\mathrm{m})\end{array}$ & $\begin{array}{c}\text { GPS Garmin } \\
{ }^{\circledR} \\
\text { de Navegação 12X (m) }\end{array}$ \\
\hline 0 & 599,761 & 600,583 & 594,359 & 617,618 \\
1 & 600,968 & 600,968 & 589,688 & 618,618 \\
2 & 603,115 & 603,097 & 586,984 & 622,618 \\
3 & 608,222 & 608,277 & 597,648 & 623,621 \\
4 & 610,396 & 610,470 & 603,540 & 628,623 \\
5 & 607,991 & 608,092 & 601,389 & 628,624 \\
6 & 604,315 & 604,434 & 601,081 & 628,625 \\
7 & 594,085 & 594,253 & 584,682 & 602,372 \\
8 & 584,662 & 584,833 & 574,317 & 588,371 \\
9 & 586,072 & 586,289 & 581,435 & 613,630 \\
10 & 578,221 & 578,474 & 576,123 & 606,632 \\
11 & 570,644 & 570,956 & 565,769 & 601,632 \\
12 & 573,306 & 573,623 & 569,326 & 595,633 \\
13 & 567,196 & 567,550 & 562,112 & 601,633 \\
14 & 563,324 & 563,684 & 555,217 & 569,367 \\
15 & 559,347 & 559,727 & 551,878 & 561,368 \\
16 & 566,060 & 566,528 & 554,566 & 601,629 \\
17 & 586,843 & 587,462 & 578,018 & 591,378 \\
18 & 595,089 & 595,776 & 593,960 & 602,378 \\
19 & 600,668 & 601,407 & 592,682 & 606,366 \\
\hline
\end{tabular}

Conforme BLITZKOW (1995), havia a expectativa de usar o sistema GPS para determinação de cotas, evitando, assim, a onerosa operação do nivelamento. CORSEUIL \& ROBAINA (2003), estudando a influência do tempo de coleta de dados com receptores GPS nas determinações altimétricas, constataram precisão centimétrica em altitudes, com tempos de $15 ; 10$ e 5 minutos de ocupação.

Na Tabela 3, são apresentadas as diferenças de cotas obtidas a partir dos receptores utilizados, em relação à testemunha.

Observando os valores das diferenças de cotas obtidas a partir dos equipamentos de GPS topográfico Trimble ${ }^{\circledR}$ PRO XR e GPS Garmin ${ }^{\circledR}$ de navegação $12 \mathrm{XL}$, nota-se erro muito alto para o GPS de navegação. A título de exemplo, verifique-se o ponto 16, onde o GPS geodésico apresentou variação de 0,468 , em relação à estação total, enquanto o GPS de navegação apresentou diferença de 35,569. Possivelmente, a distância da área estudada em relação à estação-base (Quatá), cerca de $200 \mathrm{~km}$, pode ter contribuído para a ocorrência de maiores divergências, embora o fabricante do equipamento GPS Pro XR informe que, no código C/A, a precisão é obtida com distâncias inferiores a $300 \mathrm{~km}$. 
TABELA 3. Diferenças das cotas (m) obtidas pelos equipamentos GPS em relação à Estação Total.

\begin{tabular}{cccc}
\hline Ponto & GPS Trimble ${ }^{\circledR} 4600$ LS & GPS Trimble ${ }^{\circledR}$ PRO XR & GPS Garmin ${ }^{\circledR}$ de Navegação 12XL \\
\hline 0 & 0,822 & 5,402 & 17,857 \\
1 & 0,000 & 11,280 & 17,650 \\
2 & 0,018 & 16,131 & 19,503 \\
3 & 0,055 & 10,574 & 15,399 \\
4 & 0,074 & 6,856 & 18,227 \\
5 & 0,101 & 6,602 & 20,633 \\
6 & 0,119 & 3,234 & 24,310 \\
7 & 0,168 & 9,403 & 8,287 \\
8 & 0,171 & 10,345 & 3,709 \\
9 & 0,217 & 4,637 & 27,558 \\
10 & 0,253 & 2,098 & 28,411 \\
11 & 0,312 & 4,875 & 30,988 \\
12 & 0,317 & 3,980 & 22,327 \\
13 & 0,354 & 5,084 & 34,437 \\
14 & 0,360 & 8,107 & 6,043 \\
15 & 0,380 & 7,469 & 2,021 \\
16 & 0,468 & 11,494 & 35,569 \\
17 & 0,619 & 8,825 & 4,535 \\
18 & 0,687 & 1,129 & 7,289 \\
19 & 0,739 & 4,986 & 5,698 \\
\hline
\end{tabular}

Na Tabela 4, são mostrados os valores obtidos da comparação estatística das cotas, respectivamente, entre o equipamento GPS Trimble ${ }^{\circledR}$ geodésico modelo 4600 LS e a Estação Total Nikon ${ }^{\circledR}$ DTM 300, utilizando teste "t", a 5\% de significância.

TABELA 4. Valores obtidos da comparação estatística de cotas entre os equipamentos GPS Trimble ${ }^{\circledR}$ geodésico modelo 4600 LS e a Estação Total Nikon ${ }^{\circledR}$ DTM 300, usando teste t $(p=5 \%)$.

\begin{tabular}{lcc}
\hline & Variável 1 & Variável 2 \\
\hline Média & 588,014 & 588,324 \\
Variância & 280,635 & 278,553 \\
Observações & 20 & 20 \\
Variância agrupada & 279,594 & \\
Hipótese da diferença de média & 0 & \\
Graus de liberdade & 38 & \\
Stat t & $-0,058$ & \\
$\mathrm{P}(\mathrm{T} \leq \mathrm{t})$ bicaudal & 0,003 & \\
$\mathrm{t}$ crítico bicaudal & 2,024 & \\
\hline
\end{tabular}

A análise dos valores da Tabela 4, para o equipamento GPS Trimble ${ }^{\circledR}$ geodésico 4600 LS, em relação à Estação Total Nikon ${ }^{\circledR}$ DTM 300, mostrou variação na primeira casa decimal (Tabela 3). A comparação estatística dos valores das cotas, utilizando teste "t" para variâncias equivalentes, permitiu observar que as médias das cotas $(\mathrm{t}=0,058608)$ para o equipamento GPS Trimble ${ }^{\circledR}$ geodésico $4600 \mathrm{LS}$ não apresentaram diferenças significativas em relação às médias obtidas com a Estação Total Nikon ${ }^{\circledR}$ DTM 300 (Tabela 4). 
$\mathrm{Na}$ Tabela 5, são mostrados os valores obtidos da comparação estatística das cotas entre o equipamento GPS Trimble ${ }^{\circledR}$ topográfico, modelo PRO XR, e a Estação Total Nikon ${ }^{\circledR}$ DTM 300, utilizando do teste " $t$ ". Nessa Tabela, a análise dos valores do equipamento GPS Trimble ${ }^{\circledR}$ PRO XR em relação à Estação Total Nikon ${ }^{\circledR}$ DTM 300 mostrou variação na unidade e, em alguns pontos, diferenças superiores à dezena (Tabela 3). A comparação estatística dos valores das cotas, utilizando o teste "t" para variâncias equivalentes, permitiu observar que as cotas $(t=1,380)$ para o equipamento GPS Trimble ${ }^{\circledR}$ PRO XR apresentaram diferenças significativas em relação às médias obtidas com a Estação Total Nikon ${ }^{\circledR}$ DTM 300.

TABELA 5. Valores obtidos da comparação estatística das cotas entre os equipamentos GPS Trimble ${ }^{\circledR}$ topográfico, modelo PRO XR, e a Estação Total Nikon ${ }^{\circledR}$ DTM 300, usando o teste " $t$ ".

\begin{tabular}{lcc}
\hline & Variável 1 & Variável 2 \\
\hline Média & 588,014 & 580,738 \\
Variância & 280,635 & 274,984 \\
Observações & 20 & 20 \\
Variância agrupada & 277,810 & \\
Hipótese da diferença de média & 0 & \\
Graus de liberdade & 38 & \\
Stat t & 1,380 & \\
$\mathrm{P}(\mathrm{T} \leq \mathrm{t})$ bicaudal & 0,175 & \\
$\mathrm{t}$ crítico bicaudal & 2,024 & \\
\hline
\end{tabular}

Os valores obtidos na Tabela 6, pelo receptor GPS Garmin, de navegação, apresentaram-se com diferenças em relação à testemunha, de mais de $34 \mathrm{~m}$.

Na Tabela 6, são mostrados os valores obtidos da comparação estatística das cotas entre o equipamento GPS Garmin ${ }^{\circledR}$ de navegação 12 XS e a Estação Total Nikon ${ }^{\circledR}$ DTM 300, utilizando o teste " t".

TABELA 6. Valores obtidos da comparação estatística das cotas entre o equipamento GPS Garmin ${ }^{\circledR}$ de navegação 12 XL e a Estação Total Nikon ${ }^{\circledR}$ DTM 300, usando o teste " $t$ ".

\begin{tabular}{lcc}
\hline & Variável 1 & Variável 2 \\
\hline Média & 588,014 & 605,536 \\
Variância & 280,635 & 343,180 \\
Observações & 20 & 20 \\
Variância agrupada & 311,908 & \\
Hipótese da diferença de média & 0 & \\
Graus de liberdade & 38 & \\
Stat t & $-3,137$ & \\
$\mathrm{P}(\mathrm{T} \leq \mathrm{t})$ bicaudal & 0,953 & \\
$\mathrm{t}$ crítico bicaudal & 2,024 & \\
\hline
\end{tabular}

A análise dos valores da diferença das cotas para o equipamento GPS Garmin ${ }^{\circledR}$ de navegação 12XL em relação à Estação Total Nikon ${ }^{\circledR}$ DTM 300 (Tabela 3) mostra a comparação estatística dos valores das cotas, utilizando o teste " $\mathrm{t}$ " para variâncias equivalentes, permitindo observar que $\mathrm{o}$ equipamento GPS Garmin ${ }^{\circledR}$ de navegação 12 XL e a Estação Total Nikon ${ }^{\circledR}$ DTM 300 apresentam 
diferenças significativas entre as médias das cotas $(\mathrm{t}=3,137)$, portanto, mostraram-se inaceitáveis para esse fim (Tabela 6).

Considerando as médias do teste $\mathrm{t}$ (Tabelas $4 ; 5$ e 6 ), os valores ficaram da seguinte forma: estação total 588,014; GPS geodésico 588,324; GPS topográfico 580,738, e GPS de navegação 605,536. As médias entre a estação total e as dos equipamentos de GPS mostraram que há grande diferença no GPS de navegação, sendo de 17,225 e de 0,309 no GPS geodésico.

Os valores obtidos pelos receptores GPS, confrontados àqueles da testemunha (Estação Total), permitem sugerir o receptor geodésico para a elaboração de planialtimetria de áreas, cujas isolinhas não devem apresentar espaçamento vertical inferior a 1,00 m. Contudo, as diferenças encontradas não permitem sua recomendação para locação de curvas de nível (esses modelos de GPS em questão), haja vista que diferenças de até $0,82 \mathrm{~m}$ entre pontos seguramente irão provocar maiores danos ao solo pelo esperado acúmulo de água de chuva em pontos de cotas baixas e conseqüente rompimento do terraço. No caso de cordões de contorno com gradiente, sequer o posicionamento de estacas seria possível.

Em que pesem essas considerações, devem ser levados em conta os equipamentos e metodologia utilizados. A rápida evolução na área da topografia exige que pesquisas sejam constantemente feitas com base nos avanços em equipamentos e metodologias.

\section{CONCLUSÕES}

O equipamento de GPS Trimble ${ }^{\circledR}$ geodésico 4600 LS apresentou precisão aceitável comparado ao equipamento de Estação Total DTM 300, podendo as cotas obtidas serem utilizadas na confecção de plantas planialtimétricas básicas para projetos rurais, contudo com espaçamento vertical entre isolinhas não inferior a $1,00 \mathrm{~m}$.

O equipamento de GPS Trimble ${ }^{\circledR}$ topográfico, modelo PRO XR, não apresentou precisão aceitável comparado ao equipamento de Estação Total DTM 300. Em altimetria, deverá ter associação com um nível de precisão para correção de valores necessários à execução de plantas planialtimétricas básicas para projetos rurais.

O receptor GPS Garmin ${ }^{\circledR}$ de navegação 12 XS apresentou valores inaceitáveis para a altimetria comparados ao equipamento de Estação Total DTM 300, não sendo recomendada sua utilização para tal finalidade.

\section{REFERÊNCIAS}

ASSOCIAÇÃO BRASILEIRA DE NORMAS TÉCNICAS - NBR 13.133: Execução de levantamento topográfico. Rio de Janeiro, 1994. 35 p.

BERALDO, P.; SOARES, S.M. GPS: Introdução e aplicações práticas. Criciúma: Editora e Livraria Luana, 1995. $150 \mathrm{p}$.

BLITZKOW, D. Posicionamento por satélite: NAVSTAR/GPS. São Paulo: Escola Politécnica, USP, 1995. $36 \mathrm{p}$.

CORSEUIL, C.W; ROBAINA, A.D. Determinação altimétrica através do sistema de posicionamento global. Mira, Santa Maria, v.33, n.5, p.673-8, 2003.

SILVA, I.; ERWES, H. Curso de atualização em topografia e GPS. São Carlos: Escola de Engenharia de São Carlos, USP, 1996. 108 p.

SILVEIRA, L.C. Fundamentos de topografia. Criciúma: Escola Brasileira de Agrimensura, Curso Técnico de Agrimensura a Distância, 2000. p.381-502. 